\title{
Correlation between health-related quality of life in the physical domain and heart rate variability in asymptomatic adults
}

\author{
Wan-Chun Lu', Nian-Sheng Tzeng ${ }^{1,2}$, Yu-Chen Kao ${ }^{3}$, Chin-Bin Yeh ${ }^{1}$, Terry B. J. Kuo ${ }^{4}$, Chuan-Chia Chang ${ }^{1 *+}$ \\ and Hsin-An Chang ${ }^{1 *+}$
}

\begin{abstract}
Background: Reduced health-related quality of life in the physical domain ( $H R Q O L_{\text {physical }}$ ) has been reported to increase risks for cardiovascular disease (CVD); however, the mechanism underlying this phenomenon is still unclear. The autonomic nervous system (ANS) that connects the body and mind is a biologically plausible candidate to investigate this mechanism. The aim of our study is to examine whether the HRQOL $L_{\text {physical }}$ independently contributes to heart rate variability (HRV), which reflects ANS activity.

Methods: We recruited 329 physically and mentally healthy adults. All participants completed Beck Anxiety Inventory, Beck Depression Inventory and World Health Organization Questionnaire on Quality of Life: Short Form-Taiwanese version (WHOQOL-BREF). They were divided into groups of individuals having high or low scores of HRQOL discriminated by the quartile value of WHOQOL-BREF. We obtained the time and frequency-domain indices of HRV, namely variance (total HRV), the low-frequency power (LF; $0.05-0.15 \mathrm{~Hz}$ ), which may reflect baroreflex function, the high-frequency power (HF; 0.15-0.40 Hz), which reflects cardiac parasympathetic activity, and the LF/HF ratio.
\end{abstract}

Results: There was an independent contribution of $\mathrm{HRQOL}_{\text {physical }}$ to explaining the variance in HRV after excluding potential confounding factors (gender, age, physical activity, alcohol use, depression and anxiety). Compared with the participants with high levels of $H R Q O L_{\text {physical, }}$ those with low levels of $H R Q O L_{\text {physical }}$ displayed significant reductions in variance and LF.

Conclusions: This study highlights the independent role of low HRQOL $L_{\text {physical }}$ in contributing to the reduced HRV in healthy adults and points to a potential underlying mechanism for HRQOL

Keywords: Quality of life, Cardiovascular disease, Autonomic nervous system

\section{Background}

Health-related quality of life (HRQOL) is becoming increasingly used for evaluating health services in clinical practice [1]. The World Health Organization has defined the HRQOL as an individual's view of himself or herself in terms of his/her hopes, objectives, values, and worries [2]. The HRQOL reflects both an individual's physical and psychological health. Aside from this, the HRQOL

\footnotetext{
* Correspondence: changcc@mail.ndmctsgh.edu.tw;

changcc@ndmctsgh.edu.tw; chang.ha@mail.ndmctsgh.edu.tw

${ }^{\dagger}$ Equal contributors

'Department of Psychiatry Tri-Service General Hospital National Defense Medical Center, No. 325, Cheng-Kung Road, Sec. 2, Nei-Hu District, 114

Taipei, Taiwan

Full list of author information is available at the end of the article
}

also reflects an individual's social status and the quality of his/her surrounding environment. All in all, an individual's physical health, psychological health, social status, and the quality of his/her surrounding environment, can all influence an individual's well-being.

A growing body of research indicates that people who report lower HRQOL have higher all-cause mortality [3-6]. Some researchers have shifted the focus of their HRQOL research to its relationship with specific disease incidence and disease outcomes to increase the understanding of why this association exists. For example, some research teams first explored whether lower HRQOL is a risk factor for cardiovascular disease (CVD). As a follow up inquisition, others also wondered that if the above mentioned 
hypothesis proved to be true, which realms of the HRQOL acts as a predictor of CVD. As they have anticipated, the results of their studies have shown that impaired HRQOL was related to high prevalence of overt CVD [7] and subsequent CVD incidence [8-10]. In addition, they all approved that impaired HRQOL in the physical domain ( $\mathrm{HRQOL}_{\text {physical }}$ ) may increase CVD risks independently of traditional CVD risk factors. However, the mechanisms associated with the link between this novel risk factor and CVD are yet to be established.

The score of the HRQOL $L_{\text {physical }}$ is rated by the partici-

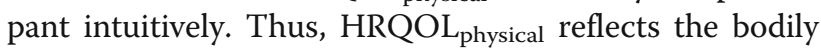
physiological health determined by certain factors perceived by the individual. This process of perception relies on an integral body-mind connection. When mindbody dissonance or disconnection [11] occurs, participants might report an unrealistically high $\mathrm{HRQOL}_{\text {physical }}$ to the investigators though they in fact had poor physical conditions [12]. In humans, the autonomic nervous system (ANS) plays important roles in flexibly adjusting the response of the body to a range of environmental demands and internal stimuli [13, 14]. A series of past studies have shown altered ANS activity among subjects with psychosomatic symptoms, which include anxiety [15], depression [16] and chronic fatigue syndrome [17]. All these findings support the idea that the ANS activity reflects the interaction between mind and body. So far various techniques have been developed to detect the ANS activity. In the last two decades, short-term frequency-domain analysis of heart rate variability has been developed as a sophisticated and non-invasive tool for detecting ANS activity [18]. Heart rate variability (HRV) refers to the complex beat-to-beat variation in heart rate measured by electrocardiogram. Variability in heart rate is produced by the sympathetic nerves, which accelerate heart rate, and the parasympathetic (vagus) nerves, which decelerate it. An increased level of HRV reflects a healthy ANS that is able to respond to environmental demands [13]. Individuals with higher levels of resting HRV have been shown to have greater abilities of emotion regulation [19]. In contrast, low HRV is an indicator of autonomic inflexibility [20] and a predictor of poor health status [21]. In the cardiovascular territory, a high degree of HRV aids healthy cardiac activity and provides a protective effect against myocardial infarction and heart failure [22], whereas decreased parasympathetic tone [23] is associated with an increased risk of CVD and mortality. All in all, HRV is a biologically plausible candidate for investigating the mechanisms underlying the contribution of $\mathrm{HRQOL}_{\text {physical }}$ to CVD risks. This in turn prompts us to raise the important question of whether there is an association between $\mathrm{HRQOL}_{\text {physical }}$ and HRV.
Most studies supporting an association existing between the HRQOL and HRV have been conducted in clinical samples with chronic illness [24-26]. The physiologic consequences of chronic illness could influence the relationship observed between HRQOL and HRV. Few studies have focused on healthy individuals in order to avoid overestimation of the association between HRQOL and HRV, but these studies' results were inconsistent $[11,27,28]$. Furthermore, these studies have the limitation of lacking a procedure to control the physical and psychiatric conditions that can confound HRV profiles. Overall, these studies have only tried to prove whether HRV predicts HRQOL. To the extent of our knowledge, no study has examined whether HRQOL $_{\text {physical }}$ and/or other domains independently affect the HRV profiles in healthy individuals.

\section{Aims of the study}

The present study aimed to test the following hypotheses: (a) there is a meaningful correlation between the $\mathrm{HRQOL}_{\text {physical }}$ and HRV; (b) in healthy subjects, the $\mathrm{HRQOL}_{\text {physical }}$ can independently contribute to HRV; and (c) the subjects with low levels of $\mathrm{HRQOL}_{\text {physical }}$ show lower HRV as compared to those with high levels of $\mathrm{HRQOL}_{\text {physical. }}$.

\section{Methods \\ Participants}

The study was approved by the local Ethics Committee TSGHIRB-099-05-171 and 2-101-05-049. Participants were informed that their clinical details in the study would be published. Written informed consent was obtained from all participants and made available to the Editor upon request. After detailed questionnaire screening, chart review, clinical examination, electrocardiography, and relevant laboratory investigations, the subjects who were pregnant or had cancer, postural hypotension, vasovagal syncope, cardiovascular, respiratory, neurological, or endocrinological disorders that affect HRV, or those engaged in regular and strenuous physical training, were excluded. Current or past smokers were also excluded. All participants were drug-naïve or had not used any medications that have been reported to affect autonomic functioning (e.g., antipsychotics, anticholinergics, antidepressants, oral contraceptives, anticonvulsants, anxiolytics, cerebral metabolic activators, or cerebral vasodilators) for at least 1 month prior to the beginning of the study. Each participant was evaluated using the Chinese version of the Modified Schedule of Affective Disorder and SchizophreniaLifetime (SADSL) [29] to exclude those with psychiatric conditions. A total of 329 healthy volunteers with valid data on both self-reported questionnaires and HRV were included in the final statistical analysis. 


\section{Control variables}

Previous findings have revealed that gender, age, body mass index (BMI), physical activity, and alcohol use are among the factors significantly affecting the autonomic control of heart rate [30-32]. These factors were thus selected as control variables. Subjects reported their average frequency of physical exercise per week (A) and the hours per session spent in purposeful exercise (B) in the past 6 months. "A" was rated with a five-point scale according to the frequency of exercise involving heavy breathing and sweating as "never", "seldom", "once a week", "twice a week", and "more than twice a week" [31]. The participants' self-reported weekly habitual physical activity was calculated by the formula: $\mathrm{A} \times \mathrm{B}$. Alcohol use, assessed with two items of the Alcohol Use Disorder Identification Test questionnaire [33], was defined by the average frequency of drinking and the number of drinks consumed on a typical drinking day in the past year. From these items, we derived the average amount of alcoholic drinks per day, with one drink defined as a standard drink, i.e., having the equivalent of $10 \mathrm{~g}$ of alcohol [34].

\section{Psychological variables: assessment of anxiety/depression severity}

Since depression [16] and anxiety [15] can profoundly influence HRV measures, all participants completed the Beck Depression Inventory (BDI) and Beck Anxiety Inventory (BAI). BDI is a 21 -item questionnaire that assesses the subjects' self-reported severity of depression [35]. Its Chinese version has a substantial internal consistency and reliability [36]. The results are scored by summing the responses to all of the items in order to obtain a total depression score (range, 0-63). The BAI contains 21 items that measure anxiety-related symptoms [37]. Its Chinese version has good test-retest reliability and fair concurrent validity [38]. Subjects were asked to rate the severity of their anxiety on 4-point Likert scales $(0-3)$. The total scores of BAI range from 0 to 63 .

\section{Measuring health-related quality of life}

HRQOL was assessed with the self-administered World Health Organization Questionnaire on Quality of Life: Short Form-Taiwanese version (WHOQOL-BREF) which was developed by the WHO to evaluate HRQOL [2] and was adapted to Taiwan's unique culture by Yao et al. [39]. The questionnaire contained 28 five-point items that assessed general (two items) and four specific domains of HRQOL, including seven items in physical health, six in psychological, four in social relationships, and nine in environmental domains, with wellestablished validity and reliability [39]. The domain scores were calculated by multiplying the mean of all item scores by a factor of four. Thus, the scores ranged from 4 to 20, with higher scores indicating better HRQOL.

\section{Measurements of blood pressure, respiratory rate and heart rate variability}

Blood pressure (BP) was recorded with a Tensoval duo control Digital Blood Pressure Monitor (HARTMANN AG, Heidenheim, Germany). Systolic BP (SBP) and diastolic BP (DBP) were measured twice from the right arm during supine rest and then averaged. The participants' respiration was recorded by using the Thought Technology Infiniti system (See also http://thoughttechnology.com/) according to the recommended procedures. An elastic band of the respirometer was adjusted to a snug, but with a comfortable tightness around participants' upper abdomen. At the end of the session the recordings were coded and saved for subsequent analysis. Movement artifacts were automatically removed by the Infiniti software from the session overview which provides a display of the total session of respiration data. The detailed procedures for the analysis of HRV were as reported in our previous studies [40, 41]. After 20 min of supine rest, a lead I electrocardiogram was taken for $5 \mathrm{~min}$ in the daytime while each subject lay quietly in a soundproof, light-controlled recording room and spontaneously breathed. Electrodes were placed on the right and left arm (Einthoven's Triangle Lead I) just below the elbow with a ground electrode placed below the wrist on the right arm. An HRV analyzer (SSIC, Enjoy Research Inc., Taipei, Taiwan) acquired, stored, and processed the electrocardiography signals. Our computer algorithm then identified each QRS complex and rejected each ventricular premature complex or noise according to its likelihood in a standard QRS template [41]. Signals were recorded at a sampling rate of $512 \mathrm{~Hz}$, using an 8-bit analogue-to-digital converter. Stationary R-R interval values were re-sampled and interpolated at a rate of $7.11 \mathrm{~Hz}$ to produce continuity in the time domain. The power spectral analysis was performed using a nonparametric fast Fourier transformation. The direct current component was deleted, and a Hamming window was used to attenuate the leakage effect [40]. The power spectrum was subsequently quantified into standard frequencydomain measurements, namely variance (variance of R-Rinterval values), very low-frequency power (VLF, 0.003$0.04 \mathrm{~Hz}$ ), low-frequency power (LF, $0.04-0.15 \mathrm{~Hz}$ ), high-frequency power $(\mathrm{HF}, 0.15-0.40 \mathrm{~Hz})$, and the ratio of LF to HF power (LF/HF). All of the measurements were logarithmically transformed to correct for a skewed distribution [42].

Vagal control of HRV is represented by HF, whereas both vagal and sympathetic control of HRV are jointly represented by LF. The LF also reflects baroreflex function during supine rest [43]. The LF/HF ratio could 
mirror sympatho-vagal balance or sympathetic modulation, with a larger LF/HF ratio indicating a greater predominance of sympathetic activity over cardiac vagal control. The VLF component has been attributed variously to thermoregulatory processes, peripheral vasomotor activity, and the renin-angiotensin system; however, its definite physiological meaning is under debate [44].

\section{Statistical analyses}

SPSS version 19.0 (SPSS Inc. Chicago, USA) statistical software was used for all analyses. All HRQOL, physiological, psychological and control variables in the present study were checked for deviations from the Gaussian distribution using the Kolmogorov-Smirnov test. Pearson's and Spearman's correlations coefficients were used to analyze the correlations between parametric and non-parametric continuous variables, respectively. Hierarchical regression analyses were used to explore the effect of HRQOL on HRV profiles after adjusting for psychological states (depression and anxiety) and control variables. The psychological states and control variables relating to HRV in univariate analysis $(p<0.05)$ were entered into step 1 of the hierarchical regression analysis, while mean $R-R$ intervals and HRV indices were the dependent variables. Data including $R^{2}, R^{2}$-changes, $F$, standardization regression coefficient $(\beta)$,and $p$ value, in the regression model are presented. Tolerance and variance inflation factors were used to check for multicollinearity. In addition, participants were divided into two groups by their scores of HRQOL $L_{\text {physical. }}$ We took the highest quartile as the point of dichotomizing HRQOL $L_{\text {physical }}$. The selection of the cut-off points in the present study was done through applying the categorization method using quartile values. Independentsamples t-tests were conducted to determine betweengroup differences in demographics and control variables. A multivariate analysis of variance (MANOVA) was performed to determine whether there were betweengroup differences on an interpretable composite of HRV variables across time and frequency-domain, and to provide a control for multiple comparisons. Analysis of covariance adjusted for any significant differences in the baseline characteristics known to affect cardiac measures. A significant Pillai's trace effect for group was followed by univariate analyses of variance (ANOVAs) to identify which measures contributed to a significant multivariate effect. Findings were corrected for multiple comparisons via Bonferroni correction. Etasquared ( $\eta 2)$ was reported for ANOVA effects as an indicator of effect size (small $=0.01$ medium $=0.06$, large $=0.14$ ). The statistical analysis was conducted at a $95 \%$ confidence level. The $\alpha$-level was set at 0.05 per comparison.

\section{Results}

\section{Sample characteristics}

The participants ranged in age from 20 to 54 years, with a mean age of $36.91 \pm 11.37$ years. The mean education level was $12.59 \pm 3.23$ years, the mean exercise level was $1.27 \pm 2.17 \mathrm{~h} /$ week and $55.3 \%$ were female. The mean BMI was $21.88 \pm 2.44 \mathrm{~kg} / \mathrm{m}^{2}$ and $32(9.7 \%)$ of our sample were underweight, 281 (85.4) \% were of normal weight and 16 (4.9\%) were overweight. The mean SBP and mean DBP were $115.91 \pm 12.80$ and $72.72 \pm 7.18 \mathrm{mmHg}$ respectively. The mean alcohol use was $0.01 \pm 0.02$ drinks/day. The scores from the WHOQOL-BREF Taiwanese version, BDI, and BAI are presented in Table 1.

\section{Factors associated with HRV profiles}

Analysis of associations between HRV indices and potential moderators were shown in Table 2. Men had significantly higher LF than women. Older participants had reduced variance (total HRV), VLF, LF and HF. Participants with higher SBP had increased VLF. The BAI score was associated with reduced variance and LF. The physical domain scores of WHOQOLBREF (HRQOL $L_{\text {physical }}$ ) positively correlated with the variance, VLF, LF, and HF. The remaining variables showed no significant association with HRV indices.

\section{Independent effects of $\mathrm{HRQOL}_{\text {physical }}$ on resting HRV profiles}

After adjusting for control variables and psychological states (BDI and BAI scores), the HRQOL physical $_{\text {scores }}$ were still associated with increased variance, VLF, LF, and HF (Table 3). Tolerance (range: 0.849-0.995) and variance inflation (range: 1.005-1.178) did not indicate multicollinearity.

\section{Heart rate variability parameters: $\mathrm{High} \mathrm{HRQOL}_{\text {physical }}$ group versus low $\mathrm{HRQOL}_{\text {physical }}$ group}

The highest quartile value of the $\mathrm{HRQOL}_{\text {physical }}$ scores of the 329 participants was 12.0. The mean breathing rate was $13.91 \pm 3.37$ breaths $/ \mathrm{min}$ for the subjects with $\mathrm{HRQOL}_{\text {physical }}$ scores above the upper quartile (high

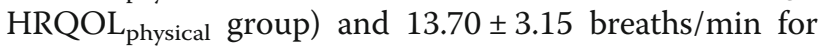
those with $\mathrm{HRQOL}_{\text {physical }}$ scores below the upper quartile (low HRQOL ${ }_{\text {physical }}$ group). The breathing rate was not significantly different between the two groups $(p=0.58)$. The high HRQOL $L_{\text {physical }}$ group had a less percentage of female participants, a lower age, BDI scores, and BAI scores but more physical activity as compared to the low HRQOL ${ }_{\text {physical }}$ group (Table 4). The MANOVA comparing the various HRV measures between high

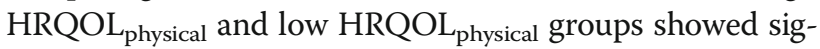
nificant results $[F(6,322)=9.67, p<0.001, \eta 2=0.153]$. The result did not significantly alter after adjusting for gender, age, physical activity, BDI scores, and BAI scores 
Table 1 Sample characteristics

\begin{tabular}{|c|c|c|c|c|}
\hline Clinical and demographic data & Number & Percent & Mean \pm SD & Range \\
\hline Males & 147 & 44.70 & & \\
\hline Females & 182 & 55.30 & & \\
\hline Age, years & 329 & & $36.91 \pm 11.37$ & $20.00-54.00$ \\
\hline Education, years & 329 & & $12.59 \pm 3.23$ & $6.00-22.00$ \\
\hline $\mathrm{BMl}, \mathrm{kg} / \mathrm{m}^{2}$ & 329 & & $21.88 \pm 2.44$ & $17.04-26.90$ \\
\hline Weekly regular exercise, hours & 329 & & $1.27 \pm 2.17$ & $0.00-9.50$ \\
\hline Alcohol use, drinks/day & 329 & & $0.01 \pm 0.02$ & $0.00-0.15$ \\
\hline $\mathrm{SBP}, \mathrm{mmHg}$ & 329 & & $115.91 \pm 12.80$ & $80.00-138.00$ \\
\hline $\mathrm{DBP}, \mathrm{mmHg}$ & 329 & & $72.72 \pm 7.18$ & $55.00-88.00$ \\
\hline BDI scores & 329 & & $5.60 \pm 3.71$ & $0.00-12.00$ \\
\hline BAl scores & 329 & & $7.85 \pm 2.73$ & $1.00-12.00$ \\
\hline \multicolumn{5}{|l|}{ WHOQOL-BREF Taiwan version } \\
\hline Scores of physical health domain & 329 & & $11.57 \pm 2.04$ & 4.00-20.00 \\
\hline Scores of psychological domain & 329 & & $13.07 \pm 2.01$ & $6.67-19.33$ \\
\hline Scores of social relationships domain & 329 & & $14.60 \pm 3.04$ & $8.00-20.00$ \\
\hline Scores of environmental domain & 329 & & $14.57 \pm 2.68$ & $5.33-19.11$ \\
\hline
\end{tabular}

Abbreviations: $S D$ standard deviation, $S B P$ systolic blood pressure, $D B P$ diastolic blood pressure, $B M I$ body mass index (calculated as weight in kilograms divided by height in meters squared), BDI Beck Depression Inventory, BAI Beck Anxiety Inventory, WHOQOL-BREF World Health Organization Questionnaire on Quality of Life: Short Form-Taiwan version

[F $(6,317)=5.40, p<0.001, \eta 2=0.093]$. A separate ANOVA was conducted for each dependent variable, with each ANOVA evaluated at an alpha level of $0.0083(0.05 / 6)$. Compared with the high $\mathrm{HRQOL}_{\text {physical }}$ group, the low $\mathrm{HRQOL}_{\text {physical }}$ group displayed significant reductions in variance $[\mathrm{F}(1322)=18.09, p<0.001$, $\eta 2=0.053$; Fig. 1], VLF $[\mathrm{F}(1322)=12.41, p<0.001$, $\eta 2=0.037]$, and $\operatorname{LF}[\mathrm{F}(1322)=9.61, p=0.002, \eta 2=0.029]$. However, the groups did not significantly differ on mean $\mathrm{R}-\mathrm{R}$ intervals [F $(1322)=2.16, p=0.14, \eta 2=0.0007]$, HF $[\mathrm{F} \quad(1322)=1.91, p=0.17, \eta 2=0.006]$, or $\mathrm{LF} / \mathrm{HF}$ ratio $[\mathrm{F}(1322)=3.89, p=0.049, \eta 2=0.012]$.

Table 2 Factors associated with resting HRV indices among all participants

\begin{tabular}{|c|c|c|c|c|c|c|}
\hline & Mean RR intervals & Var & VLF & LF & $\mathrm{HF}$ & LF/HF \\
\hline Sex(women/men) $)^{a}$ & 0.07 & 0.18 & 0.06 & $0.24^{*}$ & 0.18 & 0.07 \\
\hline $\mathrm{Age}^{\mathrm{b}}$ & 0.02 & $-0.45^{*}$ & $-0.31^{*}$ & $-0.45^{*}$ & $-0.50^{*}$ & 0.15 \\
\hline $\mathrm{BMI}^{\mathrm{b}}$ & 0.08 & 0.09 & 0.07 & 0.09 & 0.05 & 0.06 \\
\hline Physical activity ${ }^{\mathrm{b}}$ & 0.07 & 0.14 & 0.09 & 0.15 & 0.12 & 0.09 \\
\hline Alcohol use ${ }^{b}$ & 0.02 & -0.06 & -0.08 & -0.12 & -0.05 & -0.08 \\
\hline $\mathrm{SBP}^{\mathrm{b}}$ & -0.01 & -0.02 & $0.21^{*}$ & 0.00 & 0.01 & -0.01 \\
\hline $\mathrm{DBP}{ }^{\mathrm{b}}$ & 0.03 & 0.04 & 0.10 & 0.03 & 0.05 & -0.03 \\
\hline BDI scores ${ }^{b}$ & -0.15 & -0.14 & -0.15 & 0.05 & -0.17 & 0.15 \\
\hline BAl scores ${ }^{b}$ & -0.09 & $-0.19^{*}$ & -0.02 & $-0.22^{*}$ & -0.15 & -0.07 \\
\hline \multicolumn{7}{|l|}{ WHOQOL-BREF Taiwan version } \\
\hline Scores of physical health domain ${ }^{b}$ & 0.16 & $0.44^{*}$ & $0.37^{*}$ & $0.35^{*}$ & $0.30^{*}$ & 0.03 \\
\hline Scores of psychological domain ${ }^{b}$ & -0.01 & 0.12 & 0.15 & 0.08 & 0.08 & -0.02 \\
\hline Scores of social relationships domain ${ }^{b}$ & 0.05 & 0.11 & 0.12 & 0.12 & 0.04 & 0.06 \\
\hline Scores of environmental domain ${ }^{b}$ & 0.04 & 0.05 & 0.05 & -0.00 & -0.01 & 0.02 \\
\hline
\end{tabular}

Abbreviations: $B M I$ body mass index, $S B P$ systolic blood pressure, $D B P$ diastolic blood pressure, Var total variance [ln(ms2)], $V L F$, very low-frequency power [ln(ms2)], $L F$ low frequency power [In(ms2)], HF high frequency power [In(ms2)], LF/HF ratio of LF to HF [In(ratio)], BDI Beck Depression Inventory; $B A /$ Beck Anxiety Inventory, WHOQOL-BREF World Health Organization Questionnaire on Quality of Life: Short Form-Taiwan version

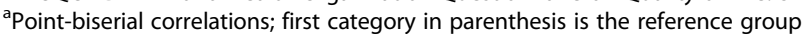

bProduct-moment correlations

${ }^{*} p<0.00064$; with a Bonferroni correction, only correlations with $p<0.00064$ were considered significant 
Table 3 Hierarchical regression analyses of mean RR intervals and all indices of heart rate variability

\begin{tabular}{|c|c|c|c|c|c|c|c|c|c|c|c|c|c|}
\hline & \multirow{2}{*}{\multicolumn{5}{|c|}{$\begin{array}{l}\text { Mean RR intervals Var VLF } \\
\text { Standardized regression coefficient and p-value }\end{array}$}} & \multirow{2}{*}{\multicolumn{3}{|c|}{ LF }} & \multicolumn{2}{|l|}{$\mathrm{HF}$} & \multicolumn{2}{|l|}{ Ratio } \\
\hline & & & & & & & & & & & & & \\
\hline & & $\beta$ & $p$ & $\beta$ & $p$ & $\beta$ & $p$ & $\beta$ & $p$ & $\beta$ & $p$ & $\beta$ & $p$ \\
\hline \multirow[t]{7}{*}{ Step 1} & Gender & - & - & 0.03 & 0.60 & 0.03 & 0.56 & 0.09 & 0.08 & 0.02 & 0.71 & - & - \\
\hline & Age & - & - & -0.40 & $<.001$ & -0.36 & $<.001$ & -0.34 & $<.001$ & -0.45 & $<.001$ & 0.14 & 0.01 \\
\hline & Physical activity & - & - & 0.14 & 0.004 & 0.12 & 0.02 & 0.16 & 0.001 & 0.10 & 0.04 & - & - \\
\hline & Alcohol use & - & - & - & - & - & - & -0.10 & 0.04 & - & - & -0.12 & 0.03 \\
\hline & $\mathrm{BDI}$ & -0.11 & 0.04 & -0.20 & $<.001$ & -0.20 & $<.001$ & - & - & -0.21 & $<.001$ & 0.15 & 0.006 \\
\hline & $\mathrm{BAl}$ & - & - & -0.21 & $<.001$ & -0.13 & 0.008 & -0.20 & $<.001$ & -0.15 & 0.002 & - & - \\
\hline & $R^{2}$ & $1.2 \%$ & & $27.4 \%$ & & $20.9 \%$ & & $24.4 \%$ & & $27.9 \%$ & & $5.5 \%$ & \\
\hline \multirow[t]{10}{*}{ Step 2} & Gender & - & - & 0.02 & 0.68 & 0.03 & 0.63 & 0.09 & 0.09 & 0.02 & 0.75 & - & - \\
\hline & Age & - & - & -0.35 & $<.001$ & -0.31 & $<.001$ & -0.31 & $<.001$ & -0.42 & $<.001$ & 0.14 & 0.01 \\
\hline & Physical activity & - & - & 0.11 & 0.02 & 0.10 & 0.04 & 0.14 & 0.003 & 0.09 & 0.07 & - & - \\
\hline & Alcohol use & - & - & - & - & - & - & -0.10 & 0.04 & - & - & -0.12 & 0.03 \\
\hline & $\mathrm{BDI}$ & -0.11 & 0.06 & -0.18 & $<.001$ & -0.18 & $<.001$ & - & - & -0.20 & $<.001$ & 0.15 & 0.006 \\
\hline & $\mathrm{BAl}$ & - & - & -0.18 & $<.001$ & -0.11 & 0.03 & -0.18 & $<.001$ & -0.13 & 0.006 & - & - \\
\hline & $\begin{array}{l}\text { WHOQOL-BREF } \\
\text { physical health domain }\end{array}$ & 0.08 & 0.17 & 0.23 & $<.001$ & 0.21 & $<.001$ & 0.16 & 0.002 & 0.11 & 0.03 & 0.06 & 0.27 \\
\hline & $R^{2}$-changes & $0.6 \%$ & & $4.8 \%$ & & $3.9 \%$ & & $2.3 \%$ & & $1.0 \%$ & & $0.3 \%$ & \\
\hline & $\mathrm{F}$ & 1.93 & & 22.92 & & 16.53 & & 10.06 & & 4.72 & & 1.12 & \\
\hline & p value & 0.17 & & $<.001$ & & $<.001$ & & 0.002 & & 0.03 & & 0.27 & \\
\hline
\end{tabular}

Abbreviations: Var total variance [In(ms2)], VLF very low-frequency power [In(ms2)], LF low frequency power [In(ms2)], $H F$ high frequency power [In(ms2)], LF/HF, ratio of LF to HF [In(ratio)], BDI Beck Depression Inventory, BAI Beck Anxiety Inventory, WHOQOL-BREF World Health Organization Questionnaire on Quality of Life: Short Form- Taiwan version

\section{Discussion}

Numerous studies have stressed that ANS activity has significant impact on HRQOL among patient population, mainly because altered ANS activity is a frequent physiological consequence of the diseases, thereby relating ANS activity to patient perceptions of
HRQOL in a unidirectional manner [12, 24-26, 45]. To date, this is the first study to examine whether HRQOL $_{\text {physical }}$ can independently contribute to HRV in a well-defined healthy population. Our study is also pioneering in raising the possibility that the relationship between ANS activity and HRQOL could be

Table 4 Characteristic differences between participants with high scores in the physical domain of QOL and low scores in the physical domain of QOL

\begin{tabular}{|c|c|c|c|}
\hline Clinical and demographic data & $\begin{array}{l}\text { High D1 domain } \\
\text { QOL scores } \geqq 12.0 \\
(N=102)\end{array}$ & $\begin{array}{l}\text { Low D1 domain } \\
\text { QOL scores }<12.0 \\
(N=227)\end{array}$ & $\overline{\text { Omnibus } p \text {-value }}$ \\
\hline Female sex (\%) & $48(26.40)$ & $134(73.60)$ & 0.03 \\
\hline Age, mean $\pm S D$, years & $33.51 \pm 10.64$ & $38.44 \pm 11.37$ & $<0.001$ \\
\hline $\mathrm{BMl}$, mean $\pm \mathrm{SD}, \mathrm{kg} / \mathrm{m}^{2}$ & $21.83 \pm 2.64$ & $21.91 \pm 2.36$ & 0.81 \\
\hline Weekly regular exercise, hours & $1.82 \pm 2.49$ & $1.02 \pm 1.97$ & 0.005 \\
\hline Alcohol use, drinks/day & $0.01 \pm 0.02$ & $0.01 \pm 0.02$ & 0.47 \\
\hline $\mathrm{SBP}, \mathrm{mmHg}$ & $115.16 \pm 12.46$ & $116.25 \pm 12.97$ & 0.48 \\
\hline $\mathrm{DBP}, \mathrm{mmHg}$ & $72.46 \pm 7.26$ & $72.84 \pm 7.16$ & 0.66 \\
\hline $\mathrm{BDI}$ scores, mean $\pm \mathrm{SD}$ & $4.82 \pm 3.65$ & $5.89 \pm 3.70$ & 0.02 \\
\hline BAl scores, mean \pm SD & $7.14 \pm 2.89$ & $8.17 \pm 2.60$ & 0.001 \\
\hline
\end{tabular}

$S D$ standard deviation, $B M I$ body mass index (calculated as weight in kilograms divided by height in meters squared), $S B P$ systolic blood pressure, $D B P$ diastolic blood pressure, $B D I$ Beck Depression Inventory, $B A$ I Beck Anxiety Inventory

D1, physical domain of WHOQOL-BREF 

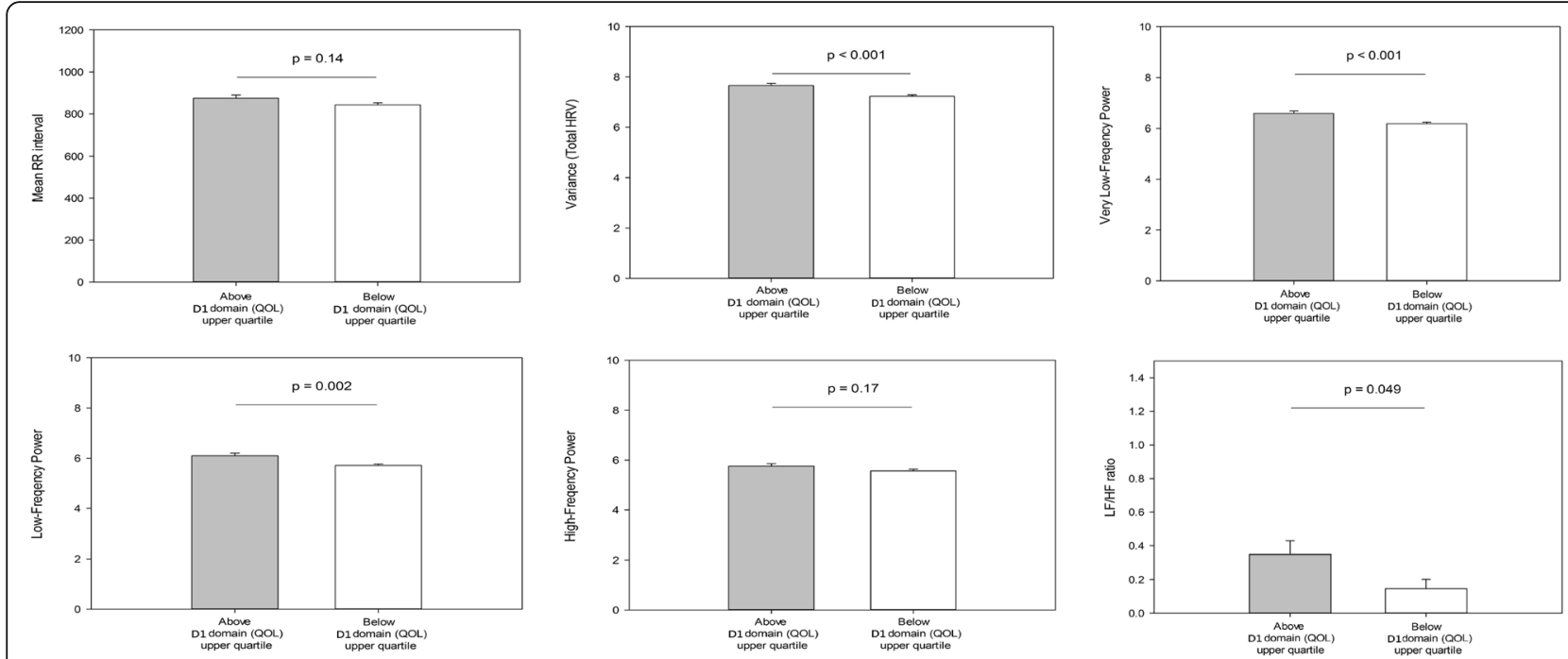

Fig. 1 Comparison of mean R-R intervals and all measures of HRV between participants with high and low quality of life in the psychological domain. Values are adjusted for gender, age, physical activity and levels of depression and anxiety. Asterisks indicate significant between-group differences. Error bars are standard error of the mean

bidirectional. The main results of our study are summed up as follows.

Our study showed a significant contribution of HRQOL $_{\text {physical }}$ to variances in HRV after excluding potential confounding factors. Consistent with this, when our participants were divided into two groups by their scores of HRQOL $L_{\text {physical }}$, those with low HRQOL $\mathrm{L}_{\text {physical }}$ exhibited significantly lower HRV as compared with

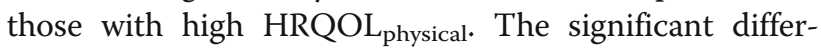
ences were not due to the levels of self-reported depression and/or anxiety because adjusting for psychological states did not alter the significance. Moreover, it should be stressed that the difference in the mean BAI scores

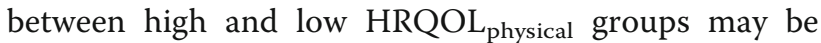
statistically significant due to a large sample size, but not be clinically significant because mean BAI scores of both groups are only within the borderline of minimal to mild level of anxiety (score 7-8). The same applied to the mean BDI scores. In the present study, the $\mathrm{HRQOL}_{\text {physical }}$ includes seven items that comprise the extent of physical pain, discomfort, energy, fatigue, and quality of sleep. The association of low HRQOL $_{\text {physical }}$ scores on HRV may be driven by the overall contributions of the impact of each item on HRV since data in the literature indicated that compared to healthy controls individuals with low energy expenditure [46, 47], sleep disturbance [48], chronic fatigue [17], or chronic pain [49] were associated with low HRV. A working conceptual model conceptualizes HRV as a process involving regulatory mechanisms of ANS, which may structurally, as well as functionally, link psychological and/or cognitive processes with health-related physiology [50]. Our study results lend further support to this model and suggest that in a healthy population $\mathrm{HRQOL}_{\text {physical }}$ may be a sensitive reflection of one's current autonomic balance or a proxy for a subclinical state or disease that are not clinically manifested yet-- it can be a measure of one's awareness of the symptoms or disease risk factors that may impact upon his or her future health outcomes especially when these factors sustained over a long period of time.

It is well known that eighty percent of CVD risk could be explained by traditional CVD risk factors including non-modifiable (i.e., age and sex) and modifiable (i.e., hypertension, smoking, diabetes, obesity and high cholesterol) ones [51, 52]. Little is known about the major determinants for the remaining twenty percent of risk in CVD. Researchers have identified reduced HRV [21, 53] and other nontraditional cardiovascular risk factors $[54,55]$ as pointers in helping to improve risk assessment. Recent studies reported that $\mathrm{HRQOL}_{\text {physical }}$ was strongly associated with cardiovascular events and CVD-specific death, and that the association was independent of traditional risk factors [56, 57]. One possibility is that the items of $\mathrm{HRQOL}_{\text {physical mainly }}$ reflect the bodily physiological health determined by other factors unmeasured in the aforementioned traditional risk calculations but perceived by individuals [8]. Another possibility is that the sum expression of the diverse items of $\mathrm{HRQOL}_{\text {physical }}$ is conceptually close to self-rated health (SRH), a simple measure of subjective health status. Much evidence already shows that $\mathrm{SRH}$ is an independent predictor of CVD incidence and cardiovascular mortality $[58,59]$, and that individuals 
who assess their health as poor have a higher mortality risk or cardiovascular events than those whose assessment is excellent [60]. However, studies in this area did not depict a clear underlying mechanism for $\mathrm{HRQOL}_{\text {physical }}$ to confer increased risk for CVD. Our study results may provide a new insight on why $\mathrm{HRQOL}_{\text {physical }}$ strongly predicts CVD health and death.

Compared to the strong link observed with HRQOL in the physical domain and HRV, the associations between psychological, social, and environmental domain and HRV were weaker and statistically not significant. This is consistent with a recent study reporting that these domains did not predict the incidence CV events [8]. This may be due to the fact that these domains are indirect indicators that reflect physical health rather than an independent predictor of autonomic balance. In our study, the psychological domain includes the extent of positive and negative feelings, thinking, self-esteem, body image, and spirit. Some constructs (e.g. pessimism and hopelessness) in this domain have been associated with increased CVD incidence and CVD-specific mortality [60, 61]. However, most studies have similarly reported a null association between the mental domain of HRQOL and CVD outcomes $[8,56]$. A possible explanation for the lack of an association is that WHOQOL-BREF is better at assessing mental health well-being, and is not designed to sensitively detect the psychological factors of cardiophysiologic significance, e.g. depression and anxiety.

Our study clearly demonstrated significant associations between psychological factors (depress and anxiety) and HRV in adjusted models (Table 3). Depression and anxiety have been related to low HRV among cardiac [62] and psychiatric patients $[15,16]$, but this relationships do not consistently exist among healthy or otherwise unselected samples [63-66]. It is conceivable that any associations observed in healthy samples may be driven by a subset of individuals who have not been evaluated formally but nonetheless meet the criteria for mood or anxiety disorder. All of our participants were evaluated with a structured diagnostic interview. This type of screening ruled out current or past psychiatric disorders. Furthermore, all participants underwent relevant laboratory investigations in addition to self-reported data of physical health. Our recent studies have emphasized this objective procedure to exclude subjects with physical comorbidities, since subjects might underestimate their biological risk factors (e.g., elevated glucose and atherogenic lipid profile) for cardiac autonomic dysregulation when these factors were self-reported [67]. Overall, our sample was well suited for studying the relationship between HRV and the factors investigated, as the effects of potential confounding factors were minimized. We believe that the above-mentioned strengths reinforce the reliability of our results.
The implications of this study's findings are potentially important to clinicians and researchers. HRQOL is the sum expression of diverse influencing factors and is not easy to determine. Our study provides a clinically helpful option of identifying a specific HRQOL domain of cardiophysiologic significance and clinical usefulness in cardiovascular prevention. If replicated, $\mathrm{HRQOL}_{\text {physical }}$ may serve as a valuable screening tool in the healthy adult population to identify those who are potentially at-risk for CVD. It may also help identify and/or elaborate those interventions to lower the incidence of CVD mortality in some people. Specifically, a 5-min HRV analysis can be done for individuals with a low $\mathrm{HRQOL}_{\text {physical }}$ scores to provide a rapid screening of systemic autonomic disturbance without much burden on them; then as a next step, those who are found to have low HRV may benefit from cardiovascular risk reduction strategies.

The main finding of the independent contribution of $\mathrm{HRQOL}_{\text {physical }}$ to explaining variance in HRV was mostly attributable to the influence that $\mathrm{HRQOL}_{\text {physical }}$ has on the VLF and LF component of spectral HRV (Table 3). Because the definite physiological meaning of VLF is under debate, we were unable to accurately interpret the finding of VLF component; nevertheless, our finding that individuals with low $\mathrm{HRQOL}_{\text {physical }}$ were associated with lower LF-HRV is of great importance. Some researchers argue that LF power in supine subjects principally reflects baroreflex sensitivity, which is a measure of the gain of the baroreflex $[43,68]$. The arterial baroreflex is the main mediator of HRV [69]. Therefore, it is possible that low HRQOL $L_{\text {physical }}$ contributes to lower baroreflex functioning, which in turn leads to reduced HRV.

The present study has two limitations. First, causality cannot be inferred from our cross-sectional data. Second, the presented regression analyses in our study revealed several statistically significant associations but the level of correlation (or regression coefficient) was low and insofar may be not physiologically relevant. The exploratory information about possible relations provided by our results requires further confirmation. Second, we classified the healthy individuals into high or low HRQOL ${ }_{\text {physical }}$ groups according to only the quartiles of the sample HRQOL $L_{\text {physical }}$ scores. The optimum $\mathrm{HRQOL}_{\text {physical }}$ scores to dichotomize healthy adults and to produce the largest contribution of a prognostic predictor to the physiologically relevant reduction in HRV should be explored in future research.

\section{Conclusions}

This study highlights the possible role of $\mathrm{HRQOL}_{\text {physical }}$ in independently contributing to the variances in HRV of asymptomatic healthy adults, and provides a new insight of the linkage between $\mathrm{HRQOL}_{\text {physical }}$ and cardiovascular risk. 


\section{Abbreviations}

ANS: Autonomic nervous system; BAl: Beck Anxiety Inventory; BDI: Beck Depression Inventory; BMI: Body mass index; CNS: Central nervous system; CVD: Cardiovascular disease; DBP: Diastolic blood pressure; HF: High frequency power; HRQOL: Health-related quality of life; HRV: Heart rate variability; LF: Low frequency power; SADSL: Schedule of Affective Disorder and Schizophrenia-Lifetime; SBP: Systolic blood pressure; WHOQOLBREF: World Health Organization Questionnaire on Quality of Life: Short Form-Taiwanese version

\section{Acknowledgement}

We would like to acknowledge and thank our study participants.

\section{Funding}

This study was funded in part by grants from the Ministry of Science and Technology of the Taiwanese Government (MOST-103-2314-B-016-021), the National Defense Medical Research (MAB-104-008), and the Teh-Tzer Study Group for Human Medical Research Foundation (A1011070, A1021012 and A1031056).

\section{Availability of data and materials}

Data cannot be shared due to local regulations on data privacy.

\section{Authors' contributions}

All authors contributed to the study concept, participated in its design, coordination and drafted the manuscript. All the authors have approved the final version of the manuscript.

\section{Competing interests}

The authors declare that they have no competing interests.

\section{Consent for publication}

Not applicable. No individual patient data reported.

\section{Ethics approval and consent to participate}

Ethical approval for the study from the institutional review boards and written informed consent from patients was obtained, where required.

\section{Author details}

${ }^{1}$ Department of Psychiatry Tri-Service General Hospital National Defense Medical Center, No. 325, Cheng-Kung Road, Sec. 2, Nei-Hu District, 114 Taipei, Taiwan. ${ }^{2}$ Student Counseling Center, National Defense Medical Center, Taipei, Taiwan. ${ }^{3}$ Department of Psychiatry, Tri-Service General Hospital Songshan Branch, Taipei, Taiwan. ${ }^{4}$ Institute of Brain Science, National Yang-Ming University, Taipei, Taiwan.

\section{Received: 17 June 2016 Accepted: 14 October 2016}

\section{Published online: 21 October 2016}

\section{References}

1. Snyder CF, Aaronson NK, Choucair AK, Elliott TE, Greenhalgh J, Halyard MY, Hess R, Miller DM, Reeve BB, Santana M. Implementing patient-reported outcomes assessment in clinical practice: a review of the options and considerations. Qual Life Res. 2012:21:1305-14

2. Development of the World Health Organization WHOQOL-BREF quality of life assessment. The WHOQOL group. Psychol Med. 1998;28:551-8.

3. Kaplan MS, Berthelot JM, Feeny D, McFarland BH, Khan S, Orpana H. The predictive validity of health-related quality of life measures: mortality in a longitudinal population-based study. Qual Life Res. 2007;16:1539-46.

4. Kroenke $\mathrm{CH}$, Kubzansky LD, Adler N, Kawachi I. Prospective change in health-related quality of life and subsequent mortality among middle-aged and older women. Am J Public Health. 2008;98:2085-91.

5. Murray C, Brett CE, Starr JM, Deary IJ. Which aspects of subjectively reported quality of life are important in predicting mortality beyond known risk factors? The Lothian Birth Cohort 1921 Study. Qual Life Res. 2011;20:81-90.

6. Xie G, Laskowitz DT, Turner EL, Egger JR, Shi P, Ren F, Gao W, Wu Y. Baseline health-related quality of life and 10-year all-cause mortality among 1739 Chinese adults. PLoS One. 2014;9:e101527.

7. Siegrist J. Impaired quality of life as a risk factor in cardiovascular disease. J Chronic Dis. 1987:40:571-8.
8. Xie G, Zou H, Myint PK, Shi P, Ren F, Gao W, Wu Y. Baseline overall healthrelated quality of life predicts the 10-year incidence of cardiovascular events in a Chinese population. Qual Life Res. 2016;25:363-71.

9. Munoz MA, Subirana I, Elosua R, Covas MI, Baena-Diez JM, Ramos R, Verdu JM, Marrugat J. Utility of a short quality of life questionnaire to predict cardiovascular events. Int J Cardiol. 2011;151:392-4.

10. Myint PK, Luben RN, Surtees PG, Wainwright NW, Wareham NJ, Khaw KT. Physical functional health predicts the incidence of coronary heart disease in the European Prospective Investigation into Cancer-Norfolk prospective population-based study. Int J Epidemiol. 2010;39:996-1003.

11. Henning MA, Sollers J, Strom JM, Hill AG, Lyndon MP, Cumin D, Hawken SJ. Junior doctors in their first year: mental health, quality of life, burnout and heart rate variability. Perspect Med Educ. 2014:3:136-43.

12. Chang LR, Lin YH, Kuo TB, Wu Chang HC, Liu CM, Liu CC, Hwu HG, Yang CC. Autonomic modulation and health-related quality of life among schizophrenic patients treated with non-intensive case management. PLoS One. 2011:6:e26378.

13. Thayer JF, Hansen AL, Saus-Rose E, Johnsen BH. Heart rate variability, prefrontal neural function, and cognitive performance: the neurovisceral integration perspective on self-regulation, adaptation, and health. Ann Behav Med. 2009:37:141-53.

14. Porges SW. Orienting in a defensive world: mammalian modifications of our evolutionary heritage. A Polyvagal Theory. Psychophysiology. 1995:32:301-18.

15. Chalmers JA, Quintana DS, Abbott MJ, Kemp AH. Anxiety disorders are associated with reduced heart rate variability: a meta-analysis. Front Psychiatry. 2014;5:80

16. Bassett D. A literature review of heart rate variability in depressive and bipolar disorders. Aust N Z J Psychiatry. 2016;50:511-9.

17. Freeman $\mathrm{R}$, Komaroff $\mathrm{AL}$. Does the chronic fatigue syndrome involve the autonomic nervous system? Am J Med. 1997:102:357-64.

18. Task Force of the European Society of Cardiology and the North American Society of Pacing and Electrophysiology. Heart rate variability: standards of measurement, physiological interpretation and clinical use. Circulation. 1996:93:1043-65.

19. Thayer JF, Ahs F, Fredrikson M, Sollers 3rd JJ, Wager TD. A meta-analysis of heart rate variability and neuroimaging studies: implications for heart rate variability as a marker of stress and health. Neurosci Biobehav Rev. 2012;36:747-56.

20. Thayer JF, Lane RD. A model of neurovisceral integration in emotion regulation and dysregulation. J Affect Disord. 2000;61:201-16.

21. Dekker JM, Crow RS, Folsom AR, Hannan PJ, Liao D, Swenne CA, Schouten EG. Low heart rate variability in a 2-min rhythm strip predicts risk of coronary heart disease and mortality from several causes: the ARIC Study. Atherosclerosis risk in communities. Circulation. 2000;102:1239-44.

22. Bigger Jr JT, Kleiger RE, Fleiss JL, Rolnitzky LM, Steinman RC, Miller JP. Components of heart rate variability measured during healing of acute myocardial infarction. Am J Cardiol. 1988:61:208-15.

23. Thayer JF, Lane RD. The role of vagal function in the risk for cardiovascular disease and mortality. Biol Psychol. 2007:74:224-42.

24. van den Berg MP, Hassink RJ, Tuinenburg AE, van Sonderen EF, Lefrandt JD, de Kam PJ, van Gelder IC, Smit AJ, Sanderman R, Crijns HJ. Quality of life in patients with paroxysmal atrial fibrillation and its predictors: importance of the autonomic nervous system. Eur Heart J. 2001:22:247-53.

25. Van Gestel AJ, Kohler M, Steier J, Teschler S, Russi EW, Teschler H. Cardiac autonomic dysfunction and health-related quality of life in patients with chronic obstructive pulmonary disease. Respirology. 2011;16:939-46.

26. Fujii H, Koyama H, Fukuda S, Tokai H, Tajima S, Koizumi J, Yamaguti K, Kuratsune $\mathrm{H}$, Watanabe $\mathrm{Y}$, Hirayama $\mathrm{Y}$, et al. Autonomic function is associated with health-related quality of life in patients with end-stage renal disease: a case-control study. J Ren Nutr. 2013;23:340-7.

27. Seifert G, Calaminus G, Wiener A, Cysarz D. Heart rate variability reflects the natural history of physiological development in healthy children and is not associated with quality of life. PLoS One. 2014;9:e91036

28. Goncalves TR, Farinatti Pde T, Gurgel IL, da Silva Soares PP. Correlation between cardiac autonomic modulation in response to orthostatic stress and indicators of quality of life, physical capacity, and physical activity in healthy individuals. J Strength Cond Res. 2015;29:1415-21.

29. Endicott J, Spitzer RL. A diagnostic interview: the schedule for affective disorders and schizophrenia. Arch Gen Psychiatry. 1978;35:837-44.

30. Antelmi I, de Paula RS, Shinzato AR, Peres CA, Mansur AJ Grupi CI. Influence of age, gender, body mass index, and functional capacity on heart rate 
variability in a cohort of subjects without heart disease. Am J Cardiol. 2004;93:381-5.

31. Henje Blom E, Olsson EM, Serlachius E, Ericson M, Ingvar M. Heart rate variability is related to self-reported physical activity in a healthy adolescent population. Eur J Appl Physiol. 2009;106:877-83.

32. Quintana DS, McGregor IS, Guastella AJ, Malhi GS, Kemp AH. A metaanalysis on the impact of alcohol dependence on short-term resting-state heart rate variability: implications for cardiovascular risk. Alcohol Clin Exp Res. 2013;37 Suppl 1:E23-29.

33. Babor TF, Fuente JR, de la Saunders J, Grant M. The alcohol use disorders identification test: guidelines for use in primary health care. Geneva: World Health Organization; 1992.

34. Li Q, Babor TF, Hao W, Chen X. The Chinese translations of Alcohol Use Disorders Identification Test (AUDIT) in China: a systematic review. Alcohol Alcohol. 2011:46:416-23.

35. Beck AT, Ward CH, Mendelson M, Mock J, Erbaugh J. An inventory for measuring depression. Arch Gen Psychiatry. 1961;4:561-71.

36. Shek DT. Reliability and factorial structure of the Chinese version of the Beck Depression Inventory. J Clin Psychol. 1990;46:35-43.

37. Beck AT, Epstein N, Brown G, Steer RA. An inventory for measuring clinical anxiety: psychometric properties. J Consult Clin Psychol. 1988;56:893-7.

38. Shek DT. The Chinese version of the State-Trait Anxiety Inventory: its relationship to different measures of psychological well-being. J Clin Psychol. 1993:49:349-58.

39. Yao G, Chung CW, Yu CF, Wang JD. Development and verification of validity and reliability of the WHOQOL-BREF Taiwan version. J Formos Med Assoc. 2002;101:342-51

40. Kuo TB, Lin T, Yang CC, Li CL, Chen CF, Chou P. Effect of aging on gender differences in neural control of heart rate. Am J Physiol. 1999:277:H2233-2239.

41. Liu CC, Kuo TB, Yang CC. Effects of estrogen on gender-related autonomic differences in humans. Am J Physiol Heart Circ Physiol. 2003;285:H2188-2193

42. Ellis RJ, Sollers lii JJ, Edelstein EA, Thayer JF. Data transforms for spectral analyses of heart rate variability. Biomed Sci Instrum. 2008;44:392-7.

43. Goldstein DS, Bentho O, Park MY, Sharabi Y. Low-frequency power of heart rate variability is not a measure of cardiac sympathetic tone but may be a measure of modulation of cardiac autonomic outflows by baroreflexes. Exp Physiol. 2011;96:1255-61.

44. Lombardi F. Clinical implications of present physiological understanding of HRV components. Card Electrophysiol Rev. 2002;6:245-9.

45. Hathaway DK, Wicks MN, Cashion AK, Cowan PA, Milstead EJ, Gaber AO Heart rate variability and quality of life following kidney and pancreaskidney transplantation. Transplant Proc. 1999;31:643-4.

46. Buchheit M, Simon C, Charloux A, Doutreleau S, Piquard F, Brandenberger G. Relationship between very high physical activity energy expenditure, heart rate variability and self-estimate of health status in middle-aged individuals. Int J Sports Med. 2006;27:697-701.

47. Buchheit M, Simon C, Charloux A, Doutreleau S, Piquard F, Brandenberger G Heart rate variability and intensity of habitual physical activity in middle-aged persons. Med Sci Sports Exerc. 2005;37:1530-4.

48. Tobaldini E, Nobili L, Strada S, Casali KR, Braghiroli A, Montano N. Heart rate variability in normal and pathological sleep. Front Physiol. 2013;4:294.

49. Koenig J, Falvay D, Clamor A, Wagner J, Jarczok MN, Ellis RJ, Weber C, Thayer JF. Pneumogastric (vagus) nerve activity indexed by heart rate variability in chronic pain patients compared to healthy controls: a systematic review and meta-analysis. Pain Physician. 2016;19:E55-78.

50. Thayer JF, Brosschot JF. Psychosomatics and psychopathology: looking up and down from the brain. Psychoneuroendocrinology. 2005;30:1050-8.

51. Grundy SM, D'Agostino Sr RB, Mosca L, Burke GL, Wilson PW, Rader DJ, Cleeman JI, Roccella EJ, Cutler JA, Friedman LM. Cardiovascular risk assessment based on US cohort studies: findings from a National Heart, Lung, and Blood institute workshop. Circulation. 2001;104:491-6.

52. Wu Y, Liu X, Li X, Li Y, Zhao L, Chen Z, Li Y, Rao X, Zhou B, Detrano R, et al. Estimation of 10-year risk of fatal and nonfatal ischemic cardiovascular diseases in Chinese adults. Circulation. 2006;114:2217-25.

53. Brook RD, Julius $\mathrm{S}$. Autonomic imbalance, hypertension, and cardiovascular risk. Am J Hypertens. 2000;13:112S-22S.

54. Yeboah J, Polonsky TS, Young R, McClelland RL, Delaney JC, Dawood F, Blaha MJ, Miedema MD, Sibley CT, Carr JJ, et al. Utility of nontraditional risk markers in individuals ineligible for statin therapy according to the 2013
American College of Cardiology/American Heart Association Cholesterol Guidelines. Circulation. 2015:132:916-22.

55. Yeboah J, Young R, McClelland RL, Delaney JC, Polonsky TS, Dawood FZ, Blaha MJ, Miedema MD, Sibley CT, Carr JJ, et al. Utility of nontraditional risk markers in atherosclerotic cardiovascular disease risk assessment. J Am Coll Cardiol. 2016;67:139-47.

56. Saquib N, Brunner R, Kubo J, Tindle H, Kroenke C, Desai M, Daviglus ML, Allen N, Martin LW, Robinson J, Stefanick ML. Self-perceived physical health predicts cardiovascular disease incidence and death among postmenopausal women. BMC Public Health. 2013;13:468.

57. van der Linde RM, Mavaddat N, Luben R, Brayne C, Simmons RK, Khaw KT, Kinmonth AL. Self-rated health and cardiovascular disease incidence: results from a longitudinal population-based cohort in Norfolk. UK PLoS One. 2013;8:e65290.

58. UI-Haq Z, Mackay DF, Pell JP. Association between self-reported general and mental health and adverse outcomes: a retrospective cohort study of 19,625 Scottish adults. PLoS One. 2014;9:e93857.

59. Mavaddat N, Parker RA, Sanderson S, Mant J, Kinmonth AL. Relationship of self-rated health with fatal and non-fatal outcomes in cardiovascular disease: a systematic review and meta-analysis. PLoS One. 2014;9:e103509.

60. Tindle HA, Chang YF, Kuller LH, Manson JE, Robinson JG, Rosal MC, Siegle GJ, Matthews KA. Optimism, cynical hostility, and incident coronary heart disease and mortality in the Women's Health Initiative. Circulation. 2009;120:656-62.

61. Stern SL, Dhanda R, Hazuda HP. Hopelessness predicts mortality in older Mexican and European Americans. Psychosom Med. 2001;63:344-51.

62. Francis $\mathrm{JL}$, Weinstein AA, Krantz DS, Haigney MC, Stein PK, Stone PH, Gottdiener JS, Kop WJ. Association between symptoms of depression and anxiety with heart rate variability in patients with implantable cardioverter defibrillators. Psychosom Med. 2009;71:821-7.

63. Bleil ME, Gianaros PJ, Jennings JR, Flory JD, Manuck SB. Trait negative affect: toward an integrated model of understanding psychological risk for impairment in cardiac autonomic function. Psychosom Med. 2008;70:328-37.

64. Ohira T, Diez Roux AV, Prineas RJ, Kizilbash MA, Carnethon MR, Folsom AR Associations of psychosocial factors with heart rate and its short-term variability: multi-ethnic study of atherosclerosis. Psychosom Med. 2008:70:141-6.

65. Virtanen R, Jula A, Salminen JK, Voipio-Pulkki LM, Helenius H, Kuusela T, Airaksinen J. Anxiety and hostility are associated with reduced baroreflex sensitivity and increased beat-to-beat blood pressure variability. Psychosom Med. 2003;65:751-6.

66. Dishman RK, Nakamura Y, Garcia ME, Thompson RW, Dunn AL, Blair SN. Heart rate variability, trait anxiety, and perceived stress among physically fit men and women. Int J Psychophysiol. 2000;37:121-33.

67. Chang CC, Chang HA, Chen TY, Fang WH, Huang SY. Brain-derived neurotrophic factor (BDNF) Val66Met polymorphism affects sympathetic tone in a gender-specific way. Psychoneuroendocrinology. 2014;47:17-25.

68. Moak JP, Goldstein DS, Eldadah BA, Saleem A, Holmes C, Pechnik S, Sharabi Y. Supine low-frequency power of heart rate variability reflects baroreflex function, not cardiac sympathetic innervation. Heart Rhythm. 2007:4:1523-9.

69. Frederiks J, Swenne CA, TenVoorde BJ, Honzikova N, Levert JV, Maan AC, Schalij MJ, Bruschke AV. The importance of high-frequency paced breathing in spectral baroreflex sensitivity assessment. J Hypertens. 2000;18:1635-44.

\section{Submit your next manuscript to BioMed Central and we will help you at every step:}

- We accept pre-submission inquiries

- Our selector tool helps you to find the most relevant journal

- We provide round the clock customer support

- Convenient online submission

- Thorough peer review

- Inclusion in PubMed and all major indexing services

- Maximum visibility for your research

Submit your manuscript at www.biomedcentral.com/submit 